\title{
When I First Encountered the Pit of an Avocado
}

\author{
Christopher Carr ${ }^{1,2}$
}

Published online: 9 September 2015

(C) Springer Science+Business Media New York 2015

When I first encountered the pit of an avocado

I thought it was beautiful

Like the cherished toy of some boy-king from long ago

Polished and cared for by a thousand servants.

I washed it thoroughly and placed it on the balcony where I dry my clothes And now I watch it fall apart and turn to dust

As the city watches me.

\section{Christopher Carr}

christopher.carr1984@gmail.com

1 Tulane University School of Medicine, New Orleans, LA, USA

2 Department of Epidemiology, Tulane University School of Public Health \& Tropical Medicine, New Orleans, LA, USA 